Editorial

\title{
Issues of Ethics and Methods in Studying Social Media
}

\author{
Niina Sormanen and Epp Lauk* \\ Department of Communication, University of Jyväskylä, 40014 Jyväskylä, Finland; E-Mails: niina.sormanen@jyu.fi (N.S.), \\ epp.lauk@jyu.fi (E.L.) \\ * Corresponding author
}

Submitted: 3 October 2016 | Published: 10 October 2016

\begin{abstract}
The Editorial raises some challenging ethical and methodological aspects of Internet based research (such as protection of informational privacy, informed consent, general ethical guidelines vs case-based approach), which are further discussed in the five articles of this special issue.
\end{abstract}

\section{Keywords}

ethics; Facebook; Internet based research; participation; social media

\section{Issue}

This editorial is part of the issue "Successes and Failures in Studying Social Media: Issues of Methods and Ethics", edited by Epp Lauk and Niina Sormanen (University of Jyväskylä, Finland).

(C) 2016 by the authors; licensee Cogitatio (Lisbon, Portugal). This article is licensed under a Creative Commons Attribution 4.0 International License (CC BY).

Along with the exponential growth of both online information and digital platforms, the emergence of the social web has increased interest towards Internet based research. Simultaneously, the debate on the issues related to the ethics and methods of this research has been expanding (e.g. Markham \& Buchanan, 2012; Moreno, Goniou, \& Moreno, 2013; Walther, 2002). Questions about ethical protection of research subjects, the ethical ways of gathering and using the data as well as the validity of the Internet based data are of the utmost importance, especially in those fields, in which human subjects are central to research. From the perspectives of research ethics and methods, online and social media seem to be the most problematic fields, as they enable a vast quantity of qualitative and quantitative approaches. Also, no general ethical rules of thumb as yet exist to guide research across all digital platforms and in accordance with the laws of particular countries.

It has been argued that the ethical problems that arise in Internet based research are basically similar to problems typical to the research within humanities and social sciences, but they still have some special aspects (Elgesem, 2002). Elgesem refers primarily to the private/public distinction, which in online environment obtains different dimensions than offline, and makes protection of informational privacy more difficult. The social media era also raises new questions, for example about the meaning of 'informed consent' in 'big data' studies; about the application of copyright principles; about anonymity and confidentiality of data; should social media be seen as a source or tool for research, etc.

The idea for this special issue originated from various unanswered questions: should the intertwined methodological and ethical choices of research be guided by, for instance, law, the cultural context, specific social media platform regulations, general ethical association guidelines such as The Association of Internet Researchers (AoIR) (see Markham \& Buchanan, 2012) or specific university ethical boards' guidelines, or perhaps scholars' own ethical decisions and common sense?

The Internet and social media platforms and sites have also defined their own specific rules of peoples' personal information and communication data usage and, for example, big data mining. For example, Facebook's user data can generally be considered public as users can individually determine the information they are willing to share publicly. However, Facebook has determined its own terms of what and how data can be 
mined for research purposes (e.g. Facebook, 2014; see also Sormanen et al., 2016). Public data, available on any social media site, does not automatically mean it has any unproblematic availability for research (e.g. Zimmer, 2010). In the user agreements of social media platforms users (information owners) have usually agreed with the use of their data for platform improvements, content optimization and marketing purposes, but not for research purposes.

In addition to ethical guidelines and any sitespecific terms and conditions, there are general codes of ethics and laws to be considered when conducting research online. For instance, for scholars operating in Finland, the two most prominent laws that define research online are the Copyright Act and the Personal Data Act. A large part of the data available on the Internet can be considered as copyrighted material, such as blog posts and photographs. The researcher should therefore use appropriate references when copying or using material or ideas available online. The Personal Data Act is a crucial guideline in conducting research online, since most of the problems and ambiguities concerning the ethics of online research tend to involve issues about informational privacy. The legal approaches, indeed, vary country by country and the way they are followed, by cultural context. Therefore, also "ethical considerations should be more case-sensitive instead of relying on one model for all solutions", as the authors of the article in this issue-"Hazy Boundaries: Virtual Communities and Research Ethics" Helena Kantanen and Jyri Manninen (2016) argue. Furthermore, online research is most often multidisciplinary and researchers have different disciplinary backgrounds. Thus, their experiences with research ethics also vary according to their specific backgrounds. Sari Östman and Riikka Turtiainen (2016), therefore, in their article "From Research Ethics to Researching Ethics in an Online Specific Context" suggest that the focus should be moved from defining general ethical guidelines to studying research ethics.

The major ethical concerns regarding social media big data research are the possible misuse and abuse of the information gathered. The risks include violations of personal privacy, civil rights and consumer freedoms (Bollier, 2010). When conducting massive data mining processes and projects, it is nearly impossible to receive consent from every individual from whom the data are collected. In these cases the researcher needs to secure the privacy of the individuals and ascertain that the information does not end up in the wrong hands and is not used for criminal purposes (see Acquisti \& Gross, 2009).

When looking at social media from big data gathering and usage perspectives, informed consent should be requested when possible even in observational research, and should not obstruct the results of the study. Social media experimental research is always more risky from the ethical perspective, and demands more reflection on its impact on the research subjects. These aspects will be further discussed in one article of the issue, "Facebook's Emotional Contagion Experiment as a Challenge to Research Ethics" by Jukka Jouhki, Epp Lauk, Maija Penttinen, Niina Sormanen and Turo Uskali (2016).

Two articles of this issue concentrate on the methodology of Internet based research. Johanna Sumiala, Minttu Tikka, Jukka Huhtamäki and Katja Valaskivi (2016), (in "\#JeSuisCharlie: Towards a Multi-Method Study of Hybrid Media Events") introduce a threephase multi-method approach for the analysis of hybrid media events. The authors outline a model, in which the research process moves from preliminary digital ethnography to quantitative social network analysis and lastly to in-depth interpretation, demonstrating how links and connections in the hybrid media landscape can be disclosed. Mikko Villi's and Janne Matikainen's (2016) article discusses a methodologically challenging issue in studying social media: "Participation in Social Media: Studying Explicit and Implicit Forms of Participation in Communicative Social Networks". They argue that too little attention has been paid to what constitutes participation when the users create connections rather than content. Unlike explicit participation, implicit participation does not involve any conscious participation, but combining different accounts (e.g. Facebook with Spotify) the users' information automatically becomes available on the other platform as well. This implicit user participation produces data that is valuable to marketers. The authors call for more attention to the research of implicit participation than has so far been employed.

The articles published in this special issue are selected from among the papers presented at the international symposium "Successes and Failures in Studying Social Media: Issues of Methods and Ethics" held on 20 November 2015 in the University of Jyväskylä, Finland.

\section{Acknowledgments}

The editors of this special issue appreciate the financial support from the University of Jyväskylä and the invaluable input of the reviewers.

\section{Conflict of Interests}

The authors declare no conflict of interests.

\section{References}

Acquisti, A., \& Gross, R. (2009). Predicting social security numbers from public data. Proceedings of the $\mathrm{Na}$ tional Academy of Science, 106(27), 10975-10980. doi:10.1073/pnas.0904891106

Bollier, D. (2010). The promise and peril of big data. 
Washington DC: The Aspen Institute. Retrieved from http://www.aspeninstitute.org/sites/default/files/co ntent/docs/pubs/The_Promise_and_Peril_of_Big_Da ta.pdf

Elgesem, D. (2002). What is special about the ethical issues in online research? Ethics and Information Technology, 4(3), 195-203.

Facebook. (2014). Statement of rights and responsibilities. Retrieved from https://www.facebook.com/ legal/terms

Jouhki, J., Lauk, E., Penttinen, M., Sormanen, N., \& Uskali, T. (2016). Facebook's emotional contagion experiment as a challenge to research ethics. Media and Communication, 4(4), 75-85.

Kantanen, H., \& Manninen, J. (2016). Hazy boundaries: Virtual communities and research ethics. Media and Communication, 4(4), 86-96.

Markham, A., \& Buchanan, E. (2012). Ethical decisionmaking and internet research. Recommendations from the AolR ethics working committee (Version 2.0). Chicago: Association of Internet Researchers. Retrieved from http://aoir.org/reports/ethics2.pdf

Moreno, M. A., Goniou, N., \& Moreno, P. S. (2013). Ethics of social media research: Common concerns and practical considerations. Cyberpsychology, Behavior, and Social Networking, 16(9), 708-713.

Östman, S., \& Turtiainen, R. (2016). From research ethics to researching ethics in an online specific context. Media and Communication, 4(4), 66-74.

Sormanen, N., Rohila, J., Lauk, E., Uskali, T., Jouhki, J., \& Penttinen, M. (2016). Chances and challenges of computational data gathering and analysis: The case of issue-attention cycles on Facebook. Digital Journalism, 4(1), 55-74. doi:10.1080/21670811.2015.109 6614

Sumiala, J., Tikka, M., Huhtamäki, J., \& Valaskivi, K. (2016). \#JeSuisCharlie: Towards a multi-method study of hybrid media events. Media and Communication, 4(4), 97-108.

Villi, M., \& Matikainen, J. (2016). Participation in social media: Studying explicit and implicit forms of participation in communicative social networks. Media and Communication, 4(4), 109-117.

Walther, J. B. (2002). Research ethics in internet-enabled research: Human subjects issues and methodological myopia. Ethics and Information Technology, 4(3), 205-216.

Zimmer, M. (2010). But the data is already public. On the ethics of research in Facebook. Ethics and Information Technology, 12(4), 313-325.

\section{About the Authors}

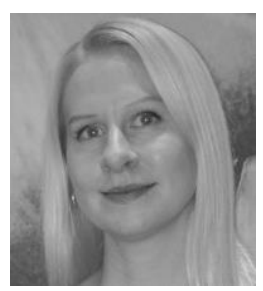

Niina Sormanen (MA) is a PhD candidate of Organizational Communication and Public Relation (PR) at the University of Jyväskylä, Department of Communication. Her research interests include communicative behavior and power relations in the social media context. Her PhD thesis is focused on the interplay of organizational and media professionals and individuals in the social media context and uses of social media in building their communicative power.

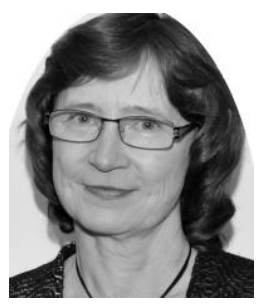

Epp Lauk (PhD) is Professor of Journalism and Head of the Department of Communication at the University of Jyväskylä, Finland. Her research and publications focus on journalism cultures and history, media and journalism in Central and East European countries, media self-regulation and innovations in journalism. 